\title{
Fertirrigação na cultura do melão em ambiente protegido, utilizando-se fertilizantes organominerais e químicos
}

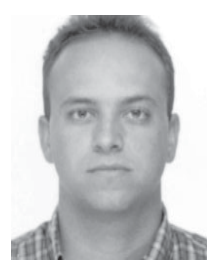

André L. T. Fernandes ${ }^{1} \&$ Roberto Testezlaf ${ }^{2}$

\footnotetext{
1 Universidade de Uberaba - Instituto de Ciências e Tecnologia do Ambiente. Av. Nenê Sabino 1801, CEP 38055-500, Uberaba, MG. E-mail: andre.fernandes@uniube.br (Foto)

2 FEAGRI/UNICAMP. E-mail: bob@agr.unicamp.br
}

Protocolo $143-23 / 10 / 2001$

\begin{abstract}
Resumo: Com este trabalho, objetivou-se monitorar a fertirrigação com biofertilizante, comparando-a com a fertirrigação química convencional, na cultura do melão variedade "Orange Flesh", cultivado em ambiente protegido. O experimento foi instalado no Campo Experimental da Universidade de Uberaba, num dos módulos de estufa plástica de $768 \mathrm{~m}^{2}$, onde foram aplicados os tratamentos: fertirrigação convencional química e com biofertilizante. Também foram estudadas, dentro dos dois tratamentos, duas freqüências de fertirrigação: diária e semanal. As melhores produtividades foram obtidas com a aplicação diária de fertilizantes, com superioridade para os produtos organominerais, com produção total de $45,5 \mathrm{t} \mathrm{ha}^{-1}$ de frutos, superior estatisticamente às $42,4 \mathrm{t} \mathrm{ha}^{-1}$ obtidas com os produtos minerais. A fertirrigação semanal resultou em produtividades inferiores às decorrentes das aplicações diárias, sendo que os produtos organominerais superaram os químicos nesse tipo de aplicação, em 2,0 t ha-1, em média. Observou-se, também, que os produtos organominerais retardaram, em cerca de $8 \mathrm{~d}$, o ciclo do melão, em comparação com os químicos. Apesar desse alongamento do ciclo da cultura, conclui-se que os produtos organominerais são extremamente eficientes na nutrição do melão, com produtividades similares e até superiores às dos produtos minerais utilizados.
\end{abstract}

Palavras-chave: Cucumis melo L. biofertilizante, freqüência

\section{Melon fertigation in greenhouse using biofertilizer and chemical fertilizers}

\begin{abstract}
The experiment was installed in the Experimental Farm of the Uberaba University, in one of the modules of plastic greenhouse of $768 \mathrm{~m}^{2}$. Treatments consisted of two types of fertigation: conventional chemical fertigation and with biofertilizers. Also, two fertigation frequencies were studied for each type: at intervals of one and seven days. The best yields were obtained with the daily fertilizer application, with superiority for the biofertilizers, with production of $45.5 \mathrm{t} \mathrm{ha}^{-1}$ of fruits. This was better than mineral products, which produced $42.4 \mathrm{t} \mathrm{ha}^{-1}$. The weekly fertigation had lower productivities, and in this case, the biofertilizers also surpassed the chemical, on an average by $2.0 \mathrm{t} \mathrm{ha}^{-1}$. It was also observed that the biofertilizers delayed the crop cycle by about 8 days, compared to chemical fertigation. In spite of prolongation of crop cycle, it can be concluded that biofertilizers are efficient in nutrition of melon, with similar or even higher yields in comparison to those obtained by mineral products.
\end{abstract}

Key words: Cucumis melo L. biofertilizer, frequency

\section{INTRODUÇÃO}

Um grande número de fertilizantes pode ser utilizado para aplicação via água de irrigação, em que os mais apropriados ou recomendados são os que apresentam alta solubilidade. Além da solubilidade, outros fatores devem ser analisados na escolha do fertilizante mais adequado para utilização em fertirrigação, como: compatibilidade, pureza, poder corrosivo, poder acidificante, possibilidade de entupimento do sistema de irrigação, custo do produto e da aplicação. Para Costa et al. (1986) embora a fertirrigação esteja sendo utilizada em algumas áreas irrigadas no Brasil, a falta de informação, principalmente sobre dosagens, tipo de fertilizantes mais recomendados, prevenção à formação de precipitados, modo e época de aplicação, reflete a necessidade de se realizar pesquisas nessa área, levando-se em consideração as diversas condições do país. De acordo com Castellanos (1998), as causas da resistência dos agricultores na adoção dessa prática são: a) razões econômicas: altos custos de investimento em comparação aos sistemas convencionais de adubação; b) razões tecnológicas: ausência de suporte técnico que permita ao produtor garantir seu investimento em tempo relativamente curto, sem colocar em risco o seu capital fixo. 
No contexto atual da agricultura irrigada, tem-se observado destaque cada vez maior para os chamados biofertilizantes, ou fertilizantes organominerais, que são produzidos através da inoculação de microrganismos em resíduos das mais diversas naturezas. A reciclagem de resíduos orgânicos, visando ao seu reaproveitamento como fonte alternativa para produção de fertilizantes, é uma medida extremamente estratégica, do ponto de vista ambiental, e por demais conveniente quando economicamente viável. Com o decreto 86.955, de 18/02/1982, aparece na lei pela primeira vez a palavra fertilizante organomineral, definida no Capítulo I das disposições preliminares, como fertilizante procedente de mistura ou combinação de fertilizantes minerais e orgânicos (Brasil, 1983). A legislação brasileira, segundo Kiehl (1994) nada mais fez que oficializar uma mistura de adubos que engenheiros agrônomos e técnicos do resto do mundo reconhecem como sendo um excelente insumo agrícola.

Segundo Kiehl (1985) a fabricação do fertilizante organomineral é feita industrialmente, partindo-se de uma ou mais matérias-primas orgânicas, e a ela se juntam corretivos, macronutrientes primários e secundários, além de micronutrientes, segundo as fórmulas de cada fabricante. Quando a matéria-prima apresenta acidez, corrige-se o $\mathrm{pH}$ antes de se juntar os nutrientes minerais. Matérias orgânicas como o lixo domiciliar e o lodo de esgoto sofrem um processo de compostagem, transformando-se em húmus para depois receberem os fertilizantes minerais. A principal razão para se adicionar certa porção de nutrientes minerais aos fertilizantes orgânicos, é diminuir a taxa de mineralização dos nutrientes, principalmente nitrogênio, fósforo e potássio. Além da necessidade de mineralização de seus compostos, para se tornar útil às plantas, os fertilizantes orgânicos têm o inconveniente de apresentar proporções fixas e definidas de NPK, diferentemente do que ocorre com as fórmulas comerciais de fertilizantes minerais, cuja composição pode ser balanceada de acordo com a planta e o solo (Kiehl, 1985).

O fertilizante organomineral se constitui num produto novo e alternativo, fruto do enriquecimento de adubos orgânicos com fertilizantes minerais. Como decorrência da maior concentração de nutrientes em relação aos fertilizantes orgânicos, apresenta a vantagem de poder ser empregado em menores quantidades por área, além do menor custo de transporte. Além disso, Kiehl (1994) observa que o fertilizante organomineral, ao contrário do químico, pode ser empregado de uma só vez no solo, pois seus nutrientes estão sob a forma orgânica e mineral. Por exemplo, o nitrogênio mineral é prontamente assimilado pelas raízes, enquanto o nitrogênio orgânico, do adubo orgânico, será absorvido pela planta quando o nitrogênio mineral já foi absorvido ou lavado pela água da chuva, ou irrigação, que atravessa o perfil do solo.

Dada à conscientização ambiental, crescente nos últimos anos, e à escassez de matérias-primas para produção de fertilizantes químicos, cresce a tendência de reaproveitamento de resíduos urbanos, industriais e agrícolas, com o intuito de despoluir o ambiente e criar novos produtos alternativos para uso na agricultura, como os fertilizantes organominerais. Devem ser analisados, porém, os riscos decorrentes da sua utilização, principalmente na fonte de matéria orgânica utilizada, com relação à possibilidade de contaminação com metais pesados e, também, no que diz respeito a danos à saúde humana. Apesar da grande potencialidade de utilização desses produtos na agricultura irrigada, são poucos os trabalhos de pesquisa relacionados à sua utilização. Dentro desse contexto, procurou-se avaliar a aplicação de adubo organomineral (biofertilizante) via água de irrigação, comparando-o com a fertirrigação convencional de adubos químicos mediante a análise de aspectos quantitativos da produção na cultura do melão (Cucumis melo L.) cultivado em ambiente protegido. Estudou-se, também, o efeito do parcelamento das fertirrigações de cobertura para o biofertilizante e para os adubos químicos.

\section{MATERIAL E MÉTODOS}

O experimento foi instalado no Campus Experimental da Universidade de Uberaba - Fazenda Escola, na cidade de Uberaba, MG, cujas coordenadas geográficas são: latitude de $19^{\circ} 44^{\prime} 13^{\prime \prime}$ S, longitude $47^{\circ} 57^{\prime} 27^{\prime \prime} \mathrm{W}$ e altitude de $850 \mathrm{~m}$. De acordo com Ranzani (1969) o clima de Uberaba é classificado pelo método de Köppen, como Aw, tropical quente e úmido, com inverno frio e seco. A precipitação anual é de $1474 \mathrm{~mm}$ e a temperatura média anual é de $22,6^{\circ} \mathrm{C}$.

$\mathrm{O}$ experimento foi instalado em um ambiente protegido de dimensões de 12,80 x 60,00 m, com pilares em madeira (pinus) tratado e estrutura metálica. $\mathrm{O}$ módulo possui as seguintes características: pé direito: $3,0 \mathrm{~m}$; altura total: $4,2 \mathrm{~m}$; fechamento lateral: tela sombrite $30 \%$; cobertura: plástico $150 \mu$, com tratamento para raios ultravioleta e orientação leste-oeste.

O sistema de irrigação era composto por um conjunto motobomba de $3 \mathrm{CV}$ com filtragem de areia e tela (120 mesh). Foram utilizados gotejadores autocompensantes, com vazão nominal de 2,3 $\mathrm{L} \mathrm{h}^{-1}$, inseridos em tubos de polietileno (PE) com espessura de parede de $0,62 \mathrm{~mm}$, diâmetro interno de $15,5 \mathrm{~mm}$ e externo de $16,7 \mathrm{~mm}$ e espaçados $0,3 \mathrm{~m}$. Como o espaçamento utilizado para a cultura de melão foi de $1,0 \mathrm{~m}$ entre linhas e de $0,3 \mathrm{~m}$ entre plantas na linha, cada planta foi irrigada por um gotejador, e as parcelas experimentais foram individualizadas por registros, cada uma com três linhas de plantas, com $15 \mathrm{~m}$ de comprimento. Utilizou-se, para injeção das soluções fertilizantes, tanto orgânicas como minerais, um injetor tipo venturi, calibrado para trabalhar na vazão de injeção de $150 \mathrm{~L} \mathrm{~h}^{-1}$.

Dentro da área experimental foram avaliadas duas fontes de fertilizantes, aplicadas via fertirrigação: o biofertilizante líquido e o adubo solúvel químico convencional, de acordo com recomendações da CATI (1999). Tanto para a fertirrigação orgânica quanto para a química, foram também estudadas duas frequiências de fertirrigação, diária e semanal. Utilizou-se o delineamento experimental fatorial $2 \times 2$, em que o fator $1 \mathrm{se}$ refere ao tipo de adubo (dois níveis A1 e A2, referentes aos produtos organominerais e químicos, respectivamente) e o fator 2 é frequiência (dois níveis $\mathrm{F} 1$ e $\mathrm{F} 2$, referentes às freqüências diária e semanal, respectivamente) com 4 repetições. Portanto, foram avaliados 4 tratamentos, denominados: a) $\mathrm{A}_{1} \mathrm{~F}_{1}$ fertirrigação com produto organomineral (A1) realizada diariamente (F1); b) $\mathrm{A}_{1} \mathrm{~F}_{2}$ - fertirrigação com produto organomineral (A1) efetuada semanalmente (F2); c) $\mathrm{A}_{2} \mathrm{~F}_{1}$ - fertirrigação com produto químico (A2) de caráter diário (F1); d) $\mathrm{A}_{2} \mathrm{~F}_{2}$ - fertirrigação com produto químico (A2) semanalmente (F2). Como 
cada tratamento teve quatro repetições, foram constituídas dezesseis parcelas experimentais. Os tratamentos foram distribuídos por sorteio dentro da área experimental e cada parcela experimental foi formada por três linhas de plantio, com 45 plantas cada uma, sendo consideradas úteis, para as análises, as plantas da linha central (Fig. 1).

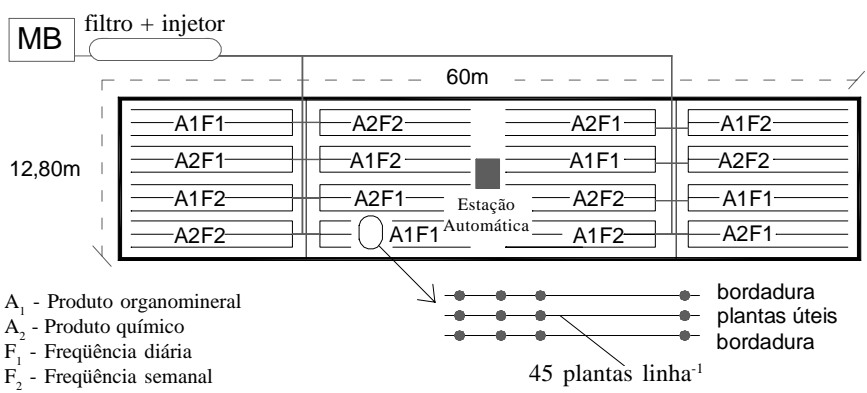

Figura 1. Esquema da área experimental e da localização das parcelas

O biofertilizante, tanto o sólido quanto o líquido, foi produzido na fábrica-piloto localizada na Fazenda Escola da Universidade de Uberaba. A matéria-prima utilizada para a fabricação do fertilizante organomineral foi a serragem de pinus, composto de lixo urbano e cama de frango produzida na fazenda, a qual passou por um processo de desodorização, desinfeção e transformação biológica, sendo produzido, desta forma, o fertilizante organomineral sólido e líquido. A adubação de fundação (plantio) dos tratamentos organominerais foi feita com fertilizante organomineral sólido, de acordo com os resultados da análise do solo (Tabela 1), na dosagem de $2 \mathrm{~kg} \mathrm{~m}^{-2}$ do organomineral sólido simples, fórmula 2-7-4, cujo procedimento foi adotado tendo em vista a característica arenosa do solo na estufa, com uma quantidade baixa de matéria orgânica, imprescindível ao desenvolvimento do melão. Como o biofertilizante possui em torno de $50 \%$ de matéria orgânica estável, adotou-se sua utilização como fonte de nutrientes no plantio. Para os tratamentos químicos, além da fonte química (fórmula 4-14-8, com aplicação de $300 \mathrm{~g} \mathrm{~m}^{-2}$ ) também foi utilizada matéria orgânica, porém de fonte convencional, com a aplicação de $2 \mathrm{~kg} \mathrm{~m}^{-2}$ de esterco de curral curtido igualando-se, desta forma, as concentrações de nitrogênio, fósforo e potássio bem próximas às do biofertilizante utilizado nos tratamentos orgânicos. $\mathrm{O}$ fertilizante organomineral sólido utilizado em adubação de plantio, teve a seguinte composição: $2,0 \%$ de nitrogênio; $7,0 \%$ de $\mathrm{P}_{2} \mathrm{O}_{5}$ total; $4,0 \%$ de $\mathrm{K}_{2} \mathrm{O} ; 2,91 \%$ de cálcio; $6,20 \%$ de enxofre, $41,51 \%$ de matéria orgânica, $\mathrm{pH}=6,6$ e $\mathrm{CTC}=55,00 \mathrm{meq}(100 \mathrm{~mL})^{-1}$.

Para a adubação de cobertura, de acordo com a análise química realizada e se respeitando os teores nutricionais do solo, utilizou-se a recomendação da CATI (1999) adotando-se as seguintes doses de nutrientes, tanto para os tratamentos químicos como para os organominerais: a) Nitrogênio: $30 \mathrm{~kg} \mathrm{ha}^{-1}$ de N, aplicados em fertirrigação; b) Potássio: $60 \mathrm{~kg} \mathrm{ha}^{-1} \mathrm{de} \mathrm{K}_{2} \mathrm{O}$, aplicados em fertirrigação; c) Fósforo: $120 \mathrm{~kg} \mathrm{ha}^{-1}$ de $\mathrm{P}_{2} \mathrm{O}_{5}$, aplicados em fertirrigação; d) Boro: $1 \mathrm{~kg} \mathrm{ha}^{-1} \mathrm{de} \mathrm{B}$, aplicado em pulverização; e) Zinco: $3 \mathrm{~kg} \mathrm{ha}^{-1} \mathrm{de} \mathrm{Zn}$, aplicados em pulverização; f) Molibdênio: $20 \mathrm{~g}(100 \mathrm{~L})^{-1}$ de água de molibdato de amônio, em 3 pulverizações: fase de 2 folhas verdadeiras; formação da primeira rama e logo após a primeira flor. O fertilizante organomineral líquido aplicado em fertirrigação, teve a seguinte composição: 2,0\% de Nitrogênio orgânico; 7,0\% de $\mathrm{P}_{2} \mathrm{O}_{5}$ (fósforo solúvel em Citrato Neutro de Amônio - água); 4,0\% de $\mathrm{K}_{2} \mathrm{O}$ (potássio solúvel em água); 38,6 \% de matéria orgânica, $\mathrm{pH}=3,2$ e $0,001 \%$ de ácido húmico. Os fertilizantes químicos aplicados foram os formulados importados, de alta solubilidade.

Cultivou-se o híbrido "Orange Flesh - Honey dew", com poder de germinação de $85 \%$ e pureza de $99 \%$. As sementes foram colocadas diretamente no solo, em 3 de outubro de 2000, previamente preparado e adubado com biofertilizante sólido para os tratamentos organominerais, e fertilizantes químicos e orgânicos convencionais, para os tratamentos químicos, no espaçamento de $1,0 \mathrm{~m}$ entre linhas e $0,3 \mathrm{~m}$ entre plantas. A cultura foi conduzida em haste única, tutorada por fios de "nylon" instalados numa malha de arame fixado em mourões de madeira, a $1,20 \mathrm{~m}$ do solo. Todos os brotos e frutos foram retirados até o $8^{\circ}$ e $10^{\circ}$ entrenós, deixando-se apenas um broto lateral a cada 2 ou 3 entrenós. Nos entrenós $12^{\circ}, 13^{\circ}$ e $14^{\circ}$ as hastes secundárias permaneceram, em virtude das flores hermafroditas que, após polinizadas por abelhas (com as janelas da estufa abertas) deram origem aos frutos. O procedimento realizado nessas hastes foi o de se retirar todos os brotos que surgiram e se fazer a capação de uma folha após o fruto. Nos entrenós posteriores, continuou-se a retirar todos os brotos, até o vigésimo, enquanto nos $21^{\circ} \stackrel{\circ}{\circ} 22^{\circ}$ e $23^{\circ}$ deixou-se crescer a haste secundária e se fez a capação da planta. Por outro lado, em cada uma das hastes secundárias deixou-se crescer uma nova brotação (hastes terciárias). Apenas 2 frutos foram deixados por planta, para garantia de boa produtividade e de maior número de frutos, em tamanho comercial. Faltando 10 dias para a colheita, retiraram-se as folhas até o $8^{\circ}$ entrenó, visando melhorar a insolação, aumentar a temperatura do solo e diminuir a taxa de evapotranspiração. Para monitoramento meteorológico dentro da estufa, foi instalada uma mini-estação agrometeorológica automática com dimensões reduzidas $(27,0 \mathrm{~cm}$ de comprimento x $11,5 \mathrm{~cm}$ de diâmetro) no centro da estrutura.

Estimou-se a evapotranspiração da cultura, pelo método de Penman Monteith. Este método é uma adaptação do modelo original de Penman, introduzindo-se os conceitos de resistência do dossel $\left(r_{c}\right)$ e de resistência aerodinâmica $\left(r_{a}\right)$ (Monteith, 1965) e é recomendado pela FAO, segundo Smith (1991). A umidade do solo foi monitorada com a leitura de tensiômetros de punção instalados em todos os tratamentos, nas profundidades de 20 , 40 e $60 \mathrm{~cm}$, com o objetivo de garantir que as parcelas estivessem recebendo a mesma lâmina de irrigação. Para determinação do tempo de irrigação foram considerados a vazão do emissor, o espaçamento entre emissores, o espaçamento entre linhas laterais e um fator de ajuste relacionado à redução da área molhada, por se tratar de irrigação localizada. A evapotranspiração da cultura $\left(\mathrm{ET}_{\mathrm{c}}\right)$ foi estimada pela Eq. 1:

$$
\mathrm{ET}_{\mathrm{c}}=\mathrm{ET}_{\mathrm{o}} \times\left(\mathrm{A}_{\mathrm{s}}\right)^{1 / 2} \times \mathrm{K}_{\mathrm{c}}
$$

sendo:

$\mathrm{ET}_{\mathrm{o}}$ - Evapotranspiração de referência, estimada pela equação de Penman Monteith, com dados da estação meteorológica automática, $\mathrm{mm} \mathrm{d}^{-1}$

$\mathrm{K}_{\mathrm{c}} \quad$ - coeficiente de cultura, decimal 
Tabela 1. Análise química do solo da estufa, antes da instalação da cultura no campo

\begin{tabular}{|c|c|c|c|c|c|c|c|c|c|c|}
\hline \multirow{2}{*}{$\begin{array}{l}\text { Profundidade } \\
\text { (cm) }\end{array}$} & \multirow{2}{*}{$\mathrm{pH}$} & $\mathrm{Al}$ & $\mathrm{Ca}$ & $\mathrm{Mg}$ & SB & $\mathrm{T}$ & $\mathrm{K}$ & $\mathrm{P}$ & \multirow{2}{*}{$\begin{array}{l}\mathrm{V} \\
\%\end{array}$} & \multirow{2}{*}{$\begin{array}{l}\text { M.O. } \\
\mathrm{g} \mathrm{kg}^{-1}\end{array}$} \\
\hline & & \multicolumn{5}{|c|}{$\mathrm{mol}_{\mathrm{c}} \mathrm{dm}^{-3}$} & \multicolumn{2}{|c|}{$\mathrm{mg} \mathrm{dm}{ }^{-3}$} & & \\
\hline $0-20$ & 6,3 & 0,0 & 2,8 & 1,2 & 4,4 & 4,4 & 144 & 186 & 81,4 & 0,9 \\
\hline $20-40$ & 4,5 & 0,4 & 0,5 & 0,3 & 1,1 & 1,5 & 120 & 2 & 40,9 & 0,9 \\
\hline
\end{tabular}

SB - soma de bases trocáveis $(\mathrm{Ca}+\mathrm{Mg}+\mathrm{K} / 39)$; $\mathrm{T}$ - CTC efetiva; $\mathrm{V}$ - saturação de bases

$$
\mathrm{K}_{\mathrm{m}}=\left(\mathrm{A}_{\mathrm{s}}\right)^{1 / 2}
$$

$\mathrm{A}_{\mathrm{s}}$ - fração da área sombreada pela cultura ao meio dia, decimal (fator de ajuste da evapotranspiração para microirrigação)

Os resultados da análise química do solo estão apresentados na Tabela 1. Segundo a classificação do Departamento de Agricultura dos Estados Unidos, o solo da área experimental é classificado como franco-arenoso. Nota-se grande diferença entre as camadas de solo, 0 a 20 e 20 a $40 \mathrm{~cm}$, principalmente relativo aos teores de fósforo e saturação de bases (V\%). Essas diferenças podem ser atribuídas à movimentação de terra (corte e aterro) ocorrida para nivelar o terreno para a instalação das estufas, alterando desta forma, a organização original das camadas do solo.

Para a avaliação da produtividade dos tratamentos, demarcaram-se, com uma fita plástica e dentro de cada parcela, 10 plantas ao acaso, cujos frutos foram colhidos em todos os tratamentos, após atingirem o ponto de colheita, definido de acordo com a cor da casca, que mudou da tonalidade verde para o amarelo claro. Em todos os frutos colhidos dessas 10 plantas, no total de três colheitas por parcela, foram feitas as seguintes medidas: a) Diâmetro dos frutos: as medidas ocorreram em todos os frutos colhidos, na porção equatorial, com paquímetro digital de precisão; precisão 0,01 mm; b) Peso: todos os frutos colhidos foram pesados em uma balança de precisão; c) Produtividade: os dados coletados por parcela foram transformados em produtividade por hectare, considerando-se a densidade da população de 33.333 plantas ha-1 $^{-1}$, no espaçamento utilizado.

Para comparação dos resultados de produtividade total, utilizou-se a metodologia de ensaios fatoriais, comparando-se os efeitos dos tipos de adubo utilizados (organomineral ou químico), das freqüências de fertirrigação (diária ou semanal) e da interação tipo do adubo x freqüência.

\section{RESULTADOS E DISCUSSÃO}

Verificam-se diferenças significativas entre os tratamentos de adubação $\left(\mathrm{F}_{\text {obtido }}=7,282\right)$ a $5 \%$ de probabilidade (Tabela 2 ), além de diferenças significativas de $1 \%$ de probabilidade, para os tratamentos de freqüência de fertirrigação $\left(\mathrm{F}_{\text {obtido }}=39,549\right)$; já para a interação tipo de adubo utilizado x freqüência de fertirrigação, não foram encontradas diferenças significativas $\left(\mathrm{F}_{\text {obtido }}=0,194\right)$. Toda a diferença entre médias estimadas igual ou superior a $6,06 \mathrm{t} \mathrm{ha}^{-1}$ deve ser considerada significativa, a $5 \%$ de probabilidade, e valores iguais ou superiores a $8,17 \mathrm{tha}^{-1}$ devem ser considerados diferentes estatisticamente, a $1 \%$ de probabilidade.

A lâmina total de água aplicada através da irrigação por gotejamento, do período do plantio até a colheita do melão, foi de $333,3 \mathrm{~mm}$, depois de finalizado o ciclo da cultura. A
Tabela 2. Análise de variância, obtido a partir das médias das parcelas, comparando-se a influência dos tratamentos de freqüência de fertirrigação e fontes de fertilizantes na produtividade total da cultura do melão

\begin{tabular}{crrrc}
\hline Causa da Variação & G.L. & \multicolumn{1}{c}{ S.Q. } & \multicolumn{1}{c}{ Q.M. } & \multicolumn{1}{c}{ F } \\
\hline Blocos & 3 & 22,628 & 7,543 & 1,001 \\
Adubação & 1 & 54,871 & 54,871 & $7,282^{*}$ \\
Freqüência & 1 & 297,994 & 297,994 & $39,549^{* *}$ \\
Interação (A x F) & 1 & 1,458 & 1,458 & 0,194 \\
Resíduo & 9 & 67,813 & 7,535 & \\
Total & 15 & 444,764 & 29,651 & \\
\hline
\end{tabular}

* significativo a $5 \%$

C.V. $=6,928 \%$

evapotranspiração de referência total, neste período, foi de 418,41 mm, estimada pelo método de Penman-Monteith, utilizando-se os dados da estação agrometeorológica automática. A profundidade atingida pelas raízes variou de 15 a $20 \mathrm{~cm}$, $25 \mathrm{~d}$ após a emergência, chegando a cerca de $50 \mathrm{~cm}$ aos $70 \mathrm{~d}$ do ciclo da cultura. A profundidade do sistema radicular do melão, segundo Marouelli (1989) pode chegar a $1 \mathrm{~m}$, em condições de clima temperado, o que não ocorreu no presente experimento, provavelmente pelo fato das aplicações de água e fertilizantes se restringirem à faixa de solo de $0 \mathrm{a} 60 \mathrm{~cm}$, a partir do controle com tensiômetros.

Em termos de ciclo total, notou-se que os tratamentos organominerais proporcionaram alongamento de $8 \mathrm{~d}$ no ciclo, que totalizou $108 \mathrm{~d}$, comparado com os $100 \mathrm{~d}$ de ciclo total do melão fertirrigado com fontes químicas de fertilizantes.

Em relação à produção por área, estão dispostos, na Tabela 3 , os valores para os diferentes tratamentos, para a produtividade comercial e não comercial, relativos à freqüências de fertirrigação e em relação aos tipos de fertilizantes avaliados.

Pela Tabela 3 verifica-se que os tratamentos de fertirrigação diária, tanto para os adubos químicos quanto para os organominerais, foram superiores estatisticamente aos tratamentos

Tabela 3. Médias* das produtividades totais, comerciais e não comerciais, em tha $\mathrm{a}^{-1}$ por tratamentos, comparando freqüência de fertirrigação (diária e semanal) e tipo de adubo utilizado (adubo químico ou fertilizante organomineral)

\begin{tabular}{ll}
\hline Freqüência & Tipo de Fertilizante \\
\cline { 2 - 2 } & Organomineral Mineral (químico) \\
\hline
\end{tabular}

$\begin{array}{lcc}\text { A. Produtividade Total } & & \\ \quad \text { Diária } & 45,5 \mathrm{a} & 42,4 \mathrm{a} \\ \text { Semanal } & 37,5 \mathrm{~b} & 33,2 \mathrm{~b} \\ \text { B. Produtividade Comercial } & & \\ \quad \text { Diária } & 31,7 & 33,6 \\ \quad \text { Semanal } & 26,7 & 25,3 \\ \text { C. Prod. Não-Comercial } & & \\ \quad \text { Diária } & 13,8 & 8,8 \\ \quad \text { Semanal } & 10,8 & 7,9 \\ \text { * As médias na produtividade total seguidas pela mesma letra minúscula não diferiram entre si, a 5\% de }\end{array}$
probabilidade pelo teste de Tukey 
de fertirrigação semanal (em média, 8,63 t ha ${ }^{-1}$ de aumento). Esta superioridade de produtividade com o uso de fertirrigações mais freqüentes, também foi verificada por Pinto et al. (1993, 1994), que conseguiram maiores produções de frutos comerciais com a aplicação diária de nutrientes via água de irrigação, e também por Sousa \& Sousa (1998) que obtiveram melhores resultados de produtividade com fertirrigações nitrogenadas e potássicas mais freqüentes (a cada $2 \mathrm{~d}$ ). Resultados semelhantes foram obtidos por Sousa et al. (1999) que alcançaram maiores produtividades comerciais e totais do meloeiro cultivado em solo arenoso no Tabuleiro Costeiro do Piauí, com freqüências de 0,5 e 1 d; já Coelho et al. (1999) em trabalho conduzido em Parnaíba, PI, avaliando a combinação de quatro intervalos de irrigação (1, 2, 3 e 4 d) com diferentes disposições das linhas laterais de gotejamento em relação à cultura de melão, chegaram à conclusão de que o intervalo entre irrigações e a disposição das linhas laterais não afetou a produtividade da cultura, explicado, provavelmente devido ao fato do aumento do intervalo de irrigação poder ter compensado o aumento do espaçamento entre linhas laterais, uma vez que a lâmina aplicada é maior para intervalos maiores e, em conseqüência, o movimento lateral de água se torna mais acentuado.

A superioridade das fontes orgânicas está relacionada, sem dúvida, ao fornecimento contínuo de nutrientes à cultura que, embora de forma mais lenta que as fontes químicas, conforme relata Kiehl (1985), permite menores perdas por lixiviação e percolação no perfil de solo, além das fontes orgânicas utilizadas estarem enriquecidas com fontes minerais solúveis. Contrariamente, Faria et al. (1994), em experimento conduzido em Juazeiro, observaram que a aplicação de matéria orgânica convencional (esterco de curral na dosagem de $15 \mathrm{~m}^{3} \mathrm{ha}^{-1}$ ) não apresenta vantagens pois, devido ao ciclo curto da cultura, não há tempo para a decomposição completa da matéria orgânica, ficando esta indisponível à cultura. Comparando-se os adubos organominerais com os químicos neste experimento, quando foi avaliada a produção por área, chegou-se a uma superioridade dos organominerais, contrariamente ao encontrado na literatura, em que a maioria dos autores tem chegado à conclusão de que a eficiência agronômica dos produtos organominerais é semelhante à dos adubos minerais, conforme relatam Pons \& Guterres (1979), Pons \& Coelho (1982), Machado et al. (1983), Tedesco \& Vogel (1983), Tedesco (1985) e Wietholter etal. (1994).

O melhor tratamento utilizado foi o caracterizado pela fertirrigação orgânica diária, superior ao tratamento fertirrigação mineral diária, evidenciando a superioridade da maior freqüência da fertirrigação na produtividade do melão. Em seguida, destacou-se a fertirrigação orgânica semanal e, por último, a fertirrigação mineral semanal.

Analisando-se a Tabela 3, verifica-se maior incidência de frutos não comerciais nos tratamentos organominerais, com porcentagens de 30,3 e $28,8 \%$, respectivamente, para fertirrigação orgânica diária e fertirrigação orgânica semanal, em relação aos tratamentos minerais. De modo geral, a colheita de frutos não comerciais no experimento pode ser considerada alta, acima de $20 \%$, comparada com a produção não comercial obtida por Pinto et al. (1993) e Souza et al. (1999).

\section{CONCLUSÕES}

1. Os tratamentos com aplicação de fontes organominerais de nutrientes, promoveram alongamento do ciclo da cultura em 8 d quando comparado aos tratamentos que receberam fertirrigações minerais.

2. Os tratamentos de fertirrigação diária, tanto para os adubos minerais quanto para os organominerais, foram superiores estatisticamente aos tratamentos de fertirrigação semanal (em média, 8,63 tha ${ }^{-1}$ de aumento).

3. A fonte de fertilizantes utilizada também teve influência significativa, porém com menor intensidade, com aumento de $3,70 \mathrm{t} \mathrm{ha}^{-1}$ para a fonte de fertilizante organomineral, comparada com a fonte mineral.

\section{LITERATURA CITADA}

Brasil. Ministério da Agricultura. Secretaria Nacional de Defesa Agropecuária. Inspeção e fiscalização da produção e do comércio de fertilizantes, corretivos, inoculantes, estimulantes ou biofertilizantes, destinados à agricultura. Brasília: Secretaria de Fiscalização Agropecuária., 1983. 86p.

Castellanos, J.Z. Princípios Básicos de Fertirrigacion. In: Seminário Internacional de Fertirrigacion, 1, 1998, Ecuador, Abstracts... Quito: Sociedade Ecuatoriana de la Ciência del Suelo, 1998. p.65-80.

CATI - Coordenadoria de Assistência Técnica Integral. Manual técnico de culturas. Campinas: CATI, 1999. CD-Rom

Coelho, E.F.; Sousa, V.F.; Rodrigues, B.H.N.; Souza, V.A.B.; Andrade, C.L.T. Produtividade do meloeiro sob diferentes intervalos de irrigação e disposições de linhas laterais de gotejamento em solo arenoso coeso. Revista Brasileira de Engenharia Agrícola e Ambiental, Campina Grande, v.3, n.3, p.309-315, 1999.

Costa, E.F.; França, G.E.; Alves, V.M.C. Aplicação de fertilizante via água de irrigação. III Curso de uso e manejo de irrigação. Informe Agropecuário, Belo Horizonte, v.12, n.129, p.63-68, 1986.

Faria, C.M.B. de; Pereira, J.R.; Possideo, E.L. de. Adubação orgânica e mineral na cultura do melão em um vertissolo do sub-médio Sao Francisco. Pesquisa Agropecuária Brasileira, Brasília, v.29, n.2, p.191-197, 1994.

Kiehl, E.J. Fertilizantes orgânicos. Piracicaba: Editora Agronômica Ceres, 1985. 492p.

Kiehl, E.J. Fertilizantes organominerais. Piracicaba: snt, 1999. 146p.

Machado, M.O.; Gomes, A.S.; Turatti, A.L.; Pauletto, E.A.; Silveira Júnior, P.S. Efeito da adubação orgânica e mineral na produção do arroz irrigado e nas propriedades químicas e físicas do solo de Pelotas. Pesquisa Agropecuária Brasileira, Brasília, v.18, n.6, p.583-591, 1983.

Marouelli, W.A.; Silva, H.R. da; Silva, W.L.C. Manejo da irrigação em hortaliças. Brasília: EMBRAPA-CNPH, 1989. 12p. Circular Técnica, 2

Monteith, J.L. Evaporation and environment. Symposium of Society of Experiment of Biology, London, v.19, p.205-234, 1965.

Pinto, J.M.; Soares, J.M.; Choudhury, E.N.; Pereira, J.R. Adubação via água de irrigação na cultura do melão. Pesquisa Agropecuária Brasileira, Brasília, v.28, n.11, p.1263-1268, 1993. 
Pinto, J.M.; Soares, J.M.; Pereira, J.R; Choudhury, E.N.; Choudhury, M.M. Efeitos de períodos e de freqüências da fertirrigação nitrogenada na produção do melão. Pesquisa Agropecuária Brasileira, Brasília, v.29, n.9, p.1345-1350, 1994.

Pons, A.L.; Coelho, C.D. Efeito do carbohumus sobre o rendimento do milho. In: Reunião Anual do Milho, 27, 1982, Porto Alegre. Anais... Porto Alegre: IPAGRO/EMATER, 1982. p.90-91.

Pons, A.L; Guterres, J.F. Efeito de diversos produtos sobre o rendimento de milho. In: Reunião Anual do Milho, 24. e Reunião do Sorgo Granífero, 8, 1979, Porto Alegre, RS. Anais... Porto Alegre: IPAGRO, 1979. p.41-43.

Ranzani, G. Manual de levantamento de solos. São Paulo: Ed. Edgard Blucher Ltda., 1969. 167p.

Smith, M. Report on the expert consultation on procedures for revision of FAO guidelines for predictions of crop water requirements. Rome: FAO. 1991. 45p.
Sousa, V.F.; Coelho, E.F.; Souza, V.A.B. Freqüência de irrigação em meloeiro cultivado em solo arenoso. Pesquisa Agropecuária Brasileira, Brasília, v.34, n.4, p.659-664, 1999.

Sousa, V.F. de; Sousa, A.de P. Efeito da freqüência de aplicação de $\mathrm{N}$ e K por gotejamento no estado nutricional e qualidade dos frutos do meloeiro (Cucumis melo L.). Engenharia Agrícola, Jaboticabal, v.17, n.3, p.36-45, 1998.

Tedesco, M.J. Resultados de experimentos com materiais orgânicos e organominerais conduzidos em casa-devegetação em 1982/83. [S.1.: s.n., 1985]. 30p. Trabalho apresentado no seminário "Eficiência agronômica de adubos orgânicos e organominerais", Passo Fundo, 1985.

Tedesco, M.J.; Vogel, E.T. Avaliação da eficiência de adubo Nitrohumomineral. Agronomia Sulriograndense, Porto Alegre, v.19, n.1, p.129-142, 1983

Wietholter, O.; Siqueira, J.F.; Peruzzo, G.; Ben. J. Efeito de fertilizantes minerais e organominerais nos rendimentos de culturas e em fatores de fertilidade do solo. Pesquisa Agropecuária Brasileira, Brasília, v.29, n.5, p.713-724, 1994. 